\title{
Effect of Five Senses Activities in the Forest on Young Children's Daily Stress
}

\author{
Hee-Chan $\mathrm{Kim}^{1}$ and Chang-Duck Koo ${ }^{2 *}$ \\ ${ }^{1}$ Graduate Department of Forest Therapy, Chungbuk National University, Cheongju 28644, Korea \\ ${ }^{2}$ Department of Forestry, Chungbuk National University, Cheongju 28644, Korea
}

\begin{abstract}
The purpose of this study was to find out the effects of five senses activities in forests on the reduction or mitigation of daily stress using various forest healing factors such as water, sunlight, topography, phytoncide, landscape, sound, fragrance, etc. The subjects of this study were 40 young children aged 5 in an early childhood education institution located in Cheongju. The children were divided into two groups: 20 in the experimental group and 20 in the control group. The experimental group participated in the program of five senses activities in the forest in total of 12 sessions ( $1-2$ sessions a week), with each session lasting 60 minutes from May 8 to June 16, 2017. The control group, who did not participate in the five senses activities in the forest, participated in the Nuri Curriculum operated by the educational institution. Before and after the program, tests to measure daily stress in three different situations (encountering blame-aggression situation, experiencing anxiety-frustration, and losing self-respect) were conducted on young children and the data were analyzed using SPSS 21.0. As a result, daily stress of the young children decreased in all three situations with statistical significance. Through the five senses activities in the forest, young children could feel the nature by observing and exploring it in the forest, so which reduced their daily stress compared to the activities carried out in the classroom.
\end{abstract}

Keywords: forest activity, forest healing, nature exploration

\section{Introduction}

The industrial society of the modern times is rapidly changing with the progress of civilization and scientific technology, and people living in this era of uncertainty about the future are suffering a great deal of stress, with the word 'stress' taking up a part of everyday lives. Stress is not experienced only by adults; young children are also exposed to stress just like adults, especially young children today who suffer more frequent and various forms of stress than the past due to the rapid social changes (Elkind, 1984). Young children's stress is classified into major life events and daily stressors depending on the intensity of stimulation. Major life events refer to parental death, divorce or health problems, whereas daily stressors are unpleasant, upsetting and startling incidents frequently experienced by young children in daily life. Daily stress felt by young children is less intense than stress from major life events but is more frequently experienced, thereby playing the most crucial role among various stress stimuli that affect them and bringing complicated effects (Band and Weisz, 1988). 
Early childhood is relatively shorter than other stages of human development but is also when the foundation for holistic development is established. Stress suffered in early childhood may undergo adolescence and even lead to adulthood. Thus, stress in early childhood has a crucial effect on the overall human development, and preschoolers and children suffer from greater stress than adolescents or adults (Moon, 1987). Moreover, unlike adults that have the ability to cope with stress faced in everyday lives, young children passively suffer in a defenseless state while lacking the ability to not only understand stress but also control the pressure on them due to their limited cognitive and linguistic abilities. Thus, they sometimes act impulsively, show aggression toward others, and undergo severe mood swings, thereby showing physically or emotionally negative behaviors or disorders (Choi, 2006).

Young children with severe stress might grow up to be emotionally unstable and even lead to physical developmental disability. Experts say that young children's stress in daily life is 'beyond their parents' imagination,' and that the effective therapy to solve various problems of young children today is to 'provide generous opportunities to encounter nature' (Choi, 2010).

Nature develops children's sensory abilities, intellectual curiosity and imagination, gives them a state of balance and peace of mind, teaches the value of life, and improves teamwork and cooperation among peers (Lim, 2006). Furthermore, Wilson (1995) strongly recommended activities in nature, claiming that experiences in the outside world during early childhood, especially opportunities to play in less structured nature, have a highly desirable impact on all areas of development such as aesthetic development, cognitive development, communication skills, sensorimotor skills, social-emotional development, and especially positive self-concept development.

Activities in the forest, which are a form of nature activities, contribute to physical, social, psychological and cognitive development of young children. A forest is a green playground in which young children can most naturally perceive, realize and experience 'the diversity of life,' and serves as a driving force that provides and promotes infinite imagination, curiosity and creativity for them, and thereby the utmost environment and open space to discover the in-depth verities of education in early childhood (Choi, 2013). Thus, when young children are given enough time to interact and commune with nature as well as to explore it, nature can most specifically and effectively unlock the potential abilities of young children as the greatest and most non-standardized textbook in the world (Park, 2005).

Studies that determined the direct correlation between activities focused on forests or nature and young children's daily stress are as follows. Han (2010) studied the effects of nature-based activities through taking walks on stress of young children, and discovered that playing in nature gives young children freedom of space and increases their confidence as they can play at will in each situation provided by nature, which helps relieve their stress. Lee (2014) claimed that while young children are engaged in forest activities, they are free from the pressure of having to do something within a certain period of time and can actually enjoy a sense of freedom, which improves their emotional stability and helps relieve stress.

The variables of microsystem affecting young children's daily stress that have the greatest explanatory power are variables related to the environment at early childhood educational institutions, which include career or work experience of teachers, academic background of teachers, number of children in each class, and interaction between teachers and young children. Young children tend to suffer from more stress when the teachers have less experience and high education level, when there are more children in each class, and when there is less interaction between teachers and young children. Considering that most educational institutions provide a standardized environment, daily stress might be caused by young children's standardized physical environment and daily activities (Park and Kim, 2003). Therefore, the objective of this study is to determine how five senses activities (non-standardized daily activities) in forests (non-standardized physical space) affect young children's daily stress. 


\section{Research Methods}

\section{Research subject and venue of the program}

\section{Method of recruitment and characteristics of subjects}

The subjects of this study are young children from an educational institution located in Cheongju, Chungcheongbuk-do contacted by the researchers. The objective and overview of this study were explained to the young children, and the guidance and consent form were approved by the director of the institution. The consent for participation of young children was obtained from their parents via newsletter and the children who expressed their voluntary will to participate became the subjects of this study after obtaining approval from the IRB (CBNU-201704-SB-445-01). Total 40 young children aged 5 participated in the study, with 20 in the experimental group (male: 9, female: 11) and 20 in the control group (male: 10, female: 10). The 20 subjects in the experimental group are young children participating in the five senses activities in the forest, while 20 in the control group are those who do not participate in the forest activities at the same institution but instead are participating in the Nuri Curriculum run by the institution.

Table 1 shows the demographic characteristics of the children by group and gender, number of children, and average age.

\section{Venue of the program}

This study was conducted from May 8 to June 16, 2017 and the experiment on the experimental group was carried out at a forest experience center for young children located in Cheongju, Chungcheongbuk-do. This center is created by the Korea Forest Service for young children to enjoy a safe forest experience, with a trail and rest area at the top of the mountain as well as sand playground and nature facilities around the area. It has little risk of negligent accidents and thus is a place with good conditions for five senses activities.

\section{Details of activities and methods}

\section{Details of activities}

The program for five senses activities selected in this study was designed by the researchers with reference to the experience games provided in 'Let's Play in the Forest' by Nam (2006) and the study on forest activities by Jang (2016). The validity of the program was verified with experts ( 2 early childhood forest instructors, 1 forest healing instructor, 1 director of the educational institution for young children, 2 early childhood teachers). The program was carried out in total 12 sessions (1-2 sessions a week), with each session lasting 60 minutes. It was designed with focus on sensory factors among various healing factors of the forest so that the children can learn about the changes in the forest and get acquainted as they see, hear, smell, touch and feel the forest.

Table 2 shows the details of each session of the program.

Table 1. Demographic characteristics of study subjects

\begin{tabular}{lcccc}
\hline Group & $\mathrm{n}$ & Male & Gender & Average age \\
\hline Experimental & 20 & 9 & 11 & 5.5 \\
Control & 20 & 10 & 10 & 5.6 \\
Total & 40 & 19 & 21 & \\
\hline
\end{tabular}




\section{Implementation stages of five senses activities in the forest}

To begin with, considering young children's physical conditions, they were to freely stand before entering the forest and do some warm-up exercises, after which they walked along the forest path with the researchers and the assistants such as the homeroom teachers and early childhood forest instructors. They moved around freely as they naturally felt the forest and talked about what they can see there, after which they were given about 10 minutes to explore the forest and perceive changes in the forest. Nature activities in the forest were carried out using the forest experience center for young children already established by the Korea Forest Service and thus there were no difficulties for young children. However, they were to participate in the activities by moving only along the created path to prevent negligent accidents, and returned to their institution after assessment.

Table 3 shows the implementation stages of the five senses activities in the forest.

\section{Assessment tool}

To measure the daily stress of young children, this study used the 'Korean Preschool Daily Stress Scale (KPDSS)' with 23 items developed by Yeom (1998).

The KPDSS is developed as a self-report scale for individual test of young children's daily stress, consisting of images for male and female and stress evaluation images to help young children better understand the items. There are total 23 items with sub-factors in 3 different situations: encountering blame-aggression situation, experiencing anxiety-frustration, and losing self-respect. The daily stress items are rated on a 4-point Likert scale from 'not stressed' 0 point, 'slightly stressed' 1 point, 'generally stressed' 2 points, and 'very stressed' 4 points, with the total score ranging from 0 to 69 points. Higher scores indicate higher level of stress.

Table 2. Details of each session program

\begin{tabular}{|c|c|c|c|}
\hline Session & Program contents & Activity contents and purpose & $\begin{array}{l}\text { Field of five senses } \\
\text { experience }\end{array}$ \\
\hline 1 & Creating a forest garden & $\begin{array}{l}\text { Understanding the importance of buds and feel the } \\
\text { touch of the soil }\end{array}$ & Touch and visual sense \\
\hline 2 & Find treasure in the forest & Observe what you see in the forest & Visual sense \\
\hline 3 & Carrying food like ants in a forest & A game of moving food together like an ant in a forest & Touch and visual sense \\
\hline 4 & Close eyes and smell the forest & Feel the various scents from the grass and trees in the forest & Olfactory sense \\
\hline 5 & Becoming a painter in the forest & Draw using various materials in the forest & Visual and touch sense \\
\hline 6 & View the forest in various ways & View the forest using a variety of tools & Visual sense \\
\hline 7 & $\begin{array}{l}\text { Find pine and oak trees } \\
\text { in the forest }\end{array}$ & $\begin{array}{l}\text { Walking through the forest road, observe the needles and } \\
\text { broad leaves and compare the fragrance }\end{array}$ & Visual and olfactory sense \\
\hline 8 & $\begin{array}{l}\text { Listen to the sounds of nature } \\
\text { in the forest }\end{array}$ & $\begin{array}{l}\text { Listen to various sounds in the forest and know the various } \\
\text { ecological elements of the forest }\end{array}$ & Auditory sense \\
\hline 9 & Try the tree in the forest & Understand the life and smell the tree & Olfactory and touch sense \\
\hline 10 & Creating a natural creation & Making natural creatures using various nature in the forest & Touch and visual sense \\
\hline 11 & $\begin{array}{l}\text { Close your eyes and } \\
\text { feel the wind in the forest }\end{array}$ & $\begin{array}{l}\text { Compare it with the wind in the forest and the wind around } \\
\text { the house and know the importance of the forest }\end{array}$ & $\begin{array}{l}\text { Auditory and } \\
\text { olfactory sense }\end{array}$ \\
\hline 12 & Making a card from leaves & $\begin{array}{l}\text { Expressing what you felt during the five senses experience } \\
\text { activity in the forest }\end{array}$ & Visual and touch sense \\
\hline
\end{tabular}




\section{Data analysis}

To test the research questions, this study calculated the mean and standard deviation of the pretest-posttest results of young children's daily stress. A t-test was conducted on the difference between the pretest and posttest to determine the difference between the experimental group and the control group. The data was analyzed using the SPSS Windows 21.0 program.

\section{Results and Discussion}

\section{Results of the pre-homogeneity test between the experimental group and control group on daily stress of young children}

Table 4 shows the result of testing the difference between the experimental group and control group on daily stress of young children before applying the five senses program in the forest to young children. As shown in Table 4, the pretest scores of the two groups did not show a significant difference overall and thus proved to be statistically homogenous groups, thereby suitable for the experiment.

\section{Effects of five senses activities in the forest on young children's daily stress}

The effects of five senses activities in the forest on young children's daily stress showed lower mean scores in the

Table 3. Implementation stage of the five senses experience activity in the forest

\begin{tabular}{lll}
\hline Stage & Time (Minute) & \multicolumn{1}{c}{ Content } \\
\hline $\begin{array}{l}\text { Preparation } \\
\text { Introduction }\end{array}$ & 5 & $\begin{array}{l}\text { Young children prepare to move to the forest. } \\
\text { Announcement of precautions to be taken in the forest. } \\
\text { Allows young children to have an interest in the forest while walking through the forest. } \\
\text { Oeployment }\end{array}$ \\
$\begin{array}{l}\text { Finishing and } \\
\text { evaluation }\end{array}$ & $10 \quad \begin{array}{l}\text { Organize a group of young children in accordance with the program of each session to perform } \\
\text { five senses activities in the forest. } \\
\text { The teacher coaches the young children to actively participate in the program. } \\
\text { Arrange surroundings after five senses experience activity. } \\
\text { Talk and share feeling through participating this five senses experience activity. }\end{array}$
\end{tabular}

Table 4. Pre-homogeneity test between experimental group and control group on daily stress $(\mathrm{N}=40)$

\begin{tabular}{|c|c|c|c|c|c|c|c|}
\hline Sub-factor & Group & $\mathrm{n}$ & M & SD & $\mathrm{t}$ & df & $p$ \\
\hline \multirow{2}{*}{ Encountering blame-aggression situation } & Experimental & 20 & 2.510 & 0.381 & \multirow{2}{*}{1.252} & \multirow{2}{*}{38} & \multirow{2}{*}{.218} \\
\hline & Control & 20 & 2.340 & 0.473 & & & \\
\hline \multirow{2}{*}{ Experiencing anxiety-frustration } & Experimental & 20 & 1.967 & 0.494 & \multirow{2}{*}{1.236} & \multirow{2}{*}{38} & \multirow{2}{*}{.22} \\
\hline & Control & 20 & 1.825 & 0.138 & & & \\
\hline \multirow{2}{*}{ Losing self-respect } & Experimental & 20 & 2.075 & 0.232 & \multirow{2}{*}{1.061} & \multirow{2}{*}{38} & \multirow{2}{*}{.295} \\
\hline & Control & 20 & 1.975 & 0.352 & & & \\
\hline \multirow{2}{*}{ Total } & Experimental & 20 & 2.113 & 0.319 & \multirow{2}{*}{1.740} & \multirow{2}{*}{38} & \multirow{2}{*}{.093} \\
\hline & Control & 20 & 1.976 & 0.149 & & & \\
\hline
\end{tabular}


experimental group than the control group as shown in Table 5.

To determine the difference in the effects between the two groups, a t-test was conducted on the mean of the differences obtained by subtracting the pretest scores from the posttest scores, and the result showed that there was a statistically significant difference.

This result supports Shin (2003) who argued that the forest is a remedy for the body and mind and can be approached in terms of healing, as it affects physiological responses of human body by relieving stress, hypertension and depression with the hygienic function of the forest, and that the diverse physical environments of the forest stimulate the sensory organs of visitors and heal their body and mind.

As a result of determining the effect on young children's stress from encountering a blame-aggression situation, which is a sub-factor of young children's daily stress, it was found that the mean score of the experimental group was lower than that of the control group, and the difference between the pretest and posttest scores was statistically significant.

This result is consistent with the study by Kim (2000) who stated that young children freely express their stress factors experienced in daily life such as tension, conflict, repression and fear through physical activities, and feel satisfied by purifying and controlling their emotions, which helps reduce stress.

As a result of determining the effect on young children's stress from experiencing anxiety-frustration, which is a sub-factor of young children's daily stress, it was found that the mean score of the experimental group was lower than that of the control group, and the difference between the pretest and posttest scores was statistically significant.

This result is consistent with the study by Jeong (1999) who stated that young children resolve emotional frustration, conflicts and tension that cause stress through play activities, and relieve negative emotions by releasing energy accumulated inside.

As a result of determining the effect on young children's stress from losing self-respect, which is a sub-factor of young children's daily stress, it was found that the mean score of the experimental group was lower than that of the control group, and the difference between the pretest and posttest scores was statistically significant.

This result is consistent with the study by Yoon (2013) who stated that young children develop confidence in nature play, through which they highly rate the value of their existence and reduce stress that affects confidence.

Table 5. Pre and post-test results by sub-factors of daily stress $(\mathrm{N}=40)$

\begin{tabular}{|c|c|c|c|c|c|c|c|c|c|c|c|}
\hline \multirow{3}{*}{ Sub-factor } & \multirow{3}{*}{ Group } & \multirow{3}{*}{$\mathrm{n}$} & \multicolumn{9}{|c|}{ Differences verification } \\
\hline & & & \multicolumn{2}{|c|}{ Before } & \multicolumn{2}{|c|}{ After } & \multicolumn{2}{|c|}{ Before-After } & \multirow{2}{*}{$\mathrm{t}$} & \multirow{2}{*}{$\mathrm{df}$} & \multirow{2}{*}{$p$} \\
\hline & & & M & $\mathrm{SD}$ & M & SD & M & SD & & & \\
\hline \multirow{2}{*}{ Encountering blame-aggression situation } & Experimental & 20 & 2.510 & 0.381 & 1.130 & 0.446 & -1.380 & 0.065 & \multirow{2}{*}{4.558} & \multirow{2}{*}{38} & \multirow{2}{*}{$.001^{*}$} \\
\hline & Control & 20 & 2.340 & 0.473 & 1.810 & 0.517 & -0.530 & 0.044 & & & \\
\hline \multirow{2}{*}{ Experiencing anxiety-frustration } & Experimental & 20 & 1.967 & 0.494 & 1.108 & 0.343 & -0.859 & -0.151 & \multirow{2}{*}{4.465} & \multirow{2}{*}{38} & \multirow{2}{*}{$.000^{*}$} \\
\hline & Control & 20 & 1.825 & 0.138 & 1.771 & 0.443 & -0.054 & 0.305 & & & \\
\hline \multirow{2}{*}{ Losing self-respect } & Experimental & 20 & 2.075 & 0.232 & 1.110 & 0.593 & -0.965 & 0.361 & \multirow{2}{*}{4.326} & \multirow{2}{*}{38} & \multirow{2}{*}{$.001^{*}$} \\
\hline & Control & 20 & 1.975 & 0.352 & 1.817 & 0.415 & -0.158 & 0.063 & & & \\
\hline \multirow{2}{*}{ Total } & Experimental & 20 & 2.113 & 0.319 & 1.111 & 0.360 & -1.002 & 0.041 & \multirow{2}{*}{5.389} & \multirow{2}{*}{38} & \multirow{2}{*}{.001} \\
\hline & Control & 20 & 1.976 & 0.149 & 1.791 & 0.369 & -0.185 & 0.220 & & & \\
\hline
\end{tabular}

${ }^{*} p<.01$ 


\section{Observation and analysis of young children participating in the five senses activities in the forest by session}

This study carried out total 12 sessions of the program, observing and recording the details of young children participating in each session.

Session 1 was to decorate a sprout hill using natural objects in the frame in groups and physically express the process of sprouts budding from the seeds through dancing. The children were very proud of their work decorating the sprout hill in groups, and seemed happy and excited as they did the sprout dancing.

Session 2 was to find natural objects they think are treasures in the forest in groups, and talk about them. There were various reasons why the children thought the objects were treasures, such as wormwood as it has a fragrance, pebbles because they can be toys, flowers because they are pretty, and clovers because they bring good luck.

Session 3 was to divide the children into groups, with a spoon in each child's mouth. The child in front placed candy on his or her spoon and passed it on to the next child behind him or her. The children showed concentration and cooperation in this activity in order not to drop the candy.

Session 4 was to close the eyes and smell the forest, and then find the plants around them that have fragrances. The teacher smelled the bags of fragrances containing plants to compare their fragrances with the plants brought by the children. Most children except a few enjoyed smelling all the plants.

Session 5 was to use the colors of fruits and flower petals in the forest to draw and do face-painting in groups. The children giggled and enjoyed watching others with face-painting.

Session 6 was to look at the sky reflected on the hand mirror placed on their noses in the forest, and look at the ground reflected on the hand mirror placed above their eyebrows. The children had fun looking at the forest that seemed so different.

Session 7 was to observe broad-leaved trees and needle-leaved trees as they walk along the forest, and comparing the number of leaves by closely observing the needle-leaved trees. The children were excited as they sang along and danced to the song that sings about two leaves of pine, three leaves of pitch pine, and five leaves of nut pine.

Session 8 was to listen to various sounds of the forest (birds, insects, winds, etc.) sitting in the forest as if meditating, talk about them, and imitate the sounds and expressing them with their body. Most children imitated birds and expressed them physically.

Session 9 was to understand what trees live on, what trees in the forest like, and what children like to eat, and also to understand the changes of the four seasons by doing exercises in the forest. They struggled with the exercises but still had fun.

Session 10 was to come up with various creations in groups using natural objects in the forest. The children made a variety of creative works such as butterflies with pine cones and leaves or boats using pine cones, leaves and twigs. They were very proud of their works.

Session 11 was to close the eyes and feel the winds in the forest, talk about the difference from the wind they feel at home, and understand the importance of the forest. Some children said that they did not like the wind they feel at home because it smells of car exhaust fumes.

Session 12 was to collect twigs and leaves in the forest and make cards using glue. The children concentrated on making the cards and were delighted by the cards they made.

As a result of observing young children that participated in five senses activities in the forest, it seemed that young children enthusiastically participated in the activities with interest and enjoyed them, looking happy. In sum, children constantly observe various living organisms in the forest with curiosity through the five senses activities, voluntarily parti- 
cipate in the activities, and build relationships as they cooperate with their friends. Moreover, the forest seems to have had a positive effect on reducing daily stress of young children by providing many opportunities for them to laugh, dance, do things freely, dream, and experience communion with nature.

The results show that five senses activities in the forest had positive effects on reducing young children's stress from encountering blame-aggression situation, stress from experiencing anxiety-frustration, and stress from losing self-respect, thereby proving to be suitable activities for young children aged 5 .

\section{Conclusion}

The analysis of the study results showed that the mean score of the experimental group that participated in the five senses activities in the forest was lower than that of the control group that participated in the Nuri Curriculum at the institution. At-test was conducted on the mean of the difference obtained by subtracting the pretest score from the posttest score to determine the difference between the two groups, and the results showed that the difference was significant.

This result proved that five senses activities in a non-standardized and broad space of the forest rather than the small and standardized space of the classroom have more positive effects on reducing young children's daily stress. It is also consistent with the study by Yoon (2013) who stated that forest play activities had effect in reducing daily stress of young children, and the study by Lee (2014) who stated that forest experience activities had a positive impact on reducing daily stress of young children.

The following suggestions can be made for follow-up research based on the results above.

First, this study was conducted on 40 young children aged 5 to determine the effects of five senses activities in the forest on daily stress of young children. Future studies must be conducted on young children of various ages, and must determine the effects depending on the developmental abilities and individual conditions of young children.

Second, the five senses activities in the forest were carried out on children at an educational institution located in Cheongju, and thus there are limitations in generalizing the results to research on daily stress of all young children. Therefore, there is a need for follow-up research that sampled young children in various regions with different living environments nationwide.

Third, the effects of five senses activities in the forest on young children's daily stress were determined through a short-term experiment. It is necessary to conduct follow-up research that determines the effects using a long-term forest program and comparatively analyzes daily stress depending on young children's developmental stages and variables.

Fourth, it is necessary to develop various educational programs that can raise young children's interest in forests, as well as forest healing programs that can be easily adopted by educational institutions for young children.

\section{References}

Band, E.B. and J.R. Weisz. 1988. How to feel better when it feels bad: Children's perspectives on coping with everyday stress. Dev. Psychol. 24(2):247-253. DOI:10.1037/0012-1649.24.2.247

Choi, H.K. 2006. The effects of childhood personality and parenthood behavior on the young children's daily stress. Master's thesis, Sookmyung Women's University, Seoul, Korea.

Choi, S.A. 2010. The effect of nature meditation activities on preschool children's emotional intelligence and daily stress. Master's thesis, Dongguk University, Seoul, Korea.

Choi, S.N. 2013. The effect of nature experience in forest on young children's social competence and self-efficacy. Master's thesis, Korean National Open University, Seoul, Korea. 
Elkind, D. 1984. The hurried child: Growing up too fast too soon. Boston, MA: Addison-Wesley.

Han, S.B. 2010. The effects of the nature-play activities through a walk on children's stress behavior and nature-friendly attitudes. Master's thesis, Chungang University, Seoul, Korea.

Jang, C.S. 2016. Effects of the five senses experience in forest on young children's self-efficacy and creativity. Master's thesis, Chungbuk National University, Cheongju, Korea.

Jeong, G.J. 1999. Theory and practice of early childhood play. Paju, Korea: Kyoyook Book Publishing.

Kim, M.S. 2000. Effects of physical activity program on children's stress. Master's thesis, Hanyang University, Seoul, Korea.

Lee, I.W. 2014. The effects of forest experience activities upon young children's daily stress reduction. J. Korea Open Assoc. Early Child. Educ. 19(6):83-103.

Lim, J.T. 2006. Operate eco-child education program. Goyang, Korea: Knowledge Community Publishing.

Moon, M.O. 1987. A Study on the effects of constructivist early childhood curriculum. Doctoral dissertation, Ewha Womans University, Seoul, Korea.

Nam, H.C. 2006. Kids, let's play in the woods. Seoul, Korea: Chusubat by Chungrim Publishing.

Park, K.H. 2005. The effect of forest experience activity on young children's self-concept development. Master's thesis, Dongguk University, Seoul, Korea.

Park, S.H. and G.U. Kim. 2003. An analysis of microsystem variables affecting children's daily hassles. Korean J. Child Stud. 24(4):1-14.

Shin, W.S. 2003. Meaning and value of forests in urbanized environment. For. Cult. 7(3):20-23.

Wilson, R.A. 1995. Nature with young children: A natural connection. Young Child. 50(6):4-11.

Yeom, H.K. 1998. A study on the development and application of preschool children's daily stress scale. Doctoral dissertation, Ewha Womans University, Seoul, Korea.

Yoon, G.A. 2013. The effects of forest play activity upon children's daily stress reduction. Master's thesis, Seoul National University of Education, Seoul, Korea. 